\title{
Correction: New composite endpoint in early diffuse cutaneous systemic sclerosis: revisiting the provisional American College of Rheumatology Composite Response Index in Systemic Sclerosis
}

Khanna D, Huang S, Lin CJF, et al. New composite endpoint in early diffuse cutaneous systemic sclerosis: revisiting the provisional American College of Rheumatology Composite Response Index in Systemic Sclerosis. Ann Rheum Dis 2021;80:641-50. doi:10.1136/ annrheumdis-2020-219100

The results section of the abstract should read: In the development sets $(n=237)$, the proportion of participants in the active group had statistically higher improvement in $\geq 1$ of 5 core set measures versus the placebo group. For example, the proportion who improved by $\geq 20 \%$ in $\geq 3$ core set measures was $49.4 \%$ in the active versus $38.9 \%$ in the placebo; RD: $10.5 \%$, $95 \%$ CI4.9 \% to $16.1 \%$. In the validation sets $(n=117)$, the proportion who improved by $\geq 20 \%$ in $\geq 3$ core set measures was $50.3 \%$ in the active versus $35.6 \%$ in the placebo (RD: $14.8 \%, 95 \%$ CI $3.1 \%$ to $25.7 \%$ ). Similar trends were seen with larger percentage cut-offs.

The first sentence of the 'Performance of five core set measures: development data sets' section should read: The proportion of participants $(n=237$, development sets) who improved by $\geq 10 \%$ to $\geq 60 \%$ (in 5\% increments) were numerically higher in the active therapy vs placebo group for all four core set measures mRSS, HAQ-DI, PGA and CGA and for FVC\% at 5\% and $10 \%$ relative improvement the majority of the time (table 3 and figure 1 ).

The third sentence of the 'Performance of five core set measures: validation data sets' section should read: The magnitude of the effects was comparable between the development and validation sets; for example, the proportion of participants who improved by $\geq 20 \%$ in $\geq 1$ core set measure was $92.7 \%$ in active therapy vs $80.1 \%$ in the placebo group, in $\geq 2$ core set measures was $75.8 \%$ in active therapy vs $57.7 \%$ in the placebo group, in $\geq 3$ core set measures was $50.3 \%$ in active therapy vs $35.6 \%$ in the placebo group and in $\geq 4$ core set measures was $27.7 \%$ in active therapy vs $13.6 \%$ in the placebo group (table 4 and online supplemental figure 1 ).

(C) Author(s) (or their employer(s)) 2021. No commercial re-use. See rights and permissions. Published by BMJ.

Ann Rheum Dis 2021;80:e154. doi:10.1136/annrheumdis-2020-219100corr1

Check for updates 